OPEN ACCESS

Edited by:

Atsushi Tsunekawa,

Tottori University, Japan

Reviewed by:

Wang Xiukang,

Yan'an University, China

Xiliang Song,

Shandong Agricultural University,

China

*Correspondence:

Tao Wang

wangtao@lzb.ac.cn

Specialty section:

This article was submitted to

Land Use Dynamics,

a section of the journal

Frontiers in Environmental Science

Received: 07 July 2020 Accepted: 08 June 2021

Published: 30 June 2021

Citation:

Gu M, Liu S, Duan H, Wang T and Gu Z (2021) Dynamics of Community

Biomass and Soil Nutrients in the Process of Vegetation Succession of Abandoned Farmland in the Loess Plateau.

Front. Environ. Sci. 9:580775. doi: $10.3389 /$ fenvs.2021.580775

\section{Dynamics of Community Biomass and Soil Nutrients in the Process of Vegetation Succession of Abandoned Farmland in the Loess Plateau}

\author{
Menghe Gu ${ }^{1}$, Shulin Liu ${ }^{1}$, Hanchen Duan ${ }^{1}$, Tao Wang ${ }^{1 *}$ and Zhong $G u^{2}$ \\ ${ }^{1}$ Key Laboratory of Desert and Desertification, Drylands Salinization Research Station, Northwest Institute of Eco-Environment \\ and Resources, Chinese Academy of Sciences, Lanzhou, China, ${ }^{2}$ College of Agriculture, Fujian Agriculture and Forestry \\ University, Fuzhou, China
}

The interaction between vegetation and soil is important for vegetation restoration and reconstruction during the succession of abandoned farmland. We chose four kinds of abandoned farmlands with the time of 1, 6, 12, and 22 years to experiment in the Loess Plateau. The community composition, community biomass, and soil nutrients of the four kinds of abandoned farmlands were studied by the method of temporal-spatial alternation, and the interaction effects among vegetation, biomass, soil nutrients, and abandonment time were analyzed. The results showed there were 33 species belonging to 13 families during the succession and 15 species of Gramineae and Compositae, accounting for $47 \%$ of the total community species. The succession trend of abandoned farmland was as follows: The vegetation was the weed community of Heteropappus altaicus + Artemisia capillaris in the beginning of the abandonment stage and became the weed community of Tragus racemosus + Enneapogon borealis after 6 years of abandonment. Then, Leymus secalinus became the dominant population in the community after 12 years of abandonment. When the succession lasted for 22 years, the vegetation became a common advantageous community of Stipa breviflora and Cleistogenes songorica. Soil moisture (SM) was positively correlated with soil nutrients and negatively correlated with abandonment time and community biomass. Soil organic matter (SOM), soil total nitrogen (STN), and alkali hydrolyzable nitrogen (AHN) were the highest in $0-10 \mathrm{~cm}$ soil layer, showing obvious surface accumulation. The three decreased with the soil layer, and there was a positive correlation among them. The abandonment time had a positive effect on the above-ground biomass (AGB) and below-ground biomass (BGB) and a negative effect on the SOM, STN, and AHN. The root/shoot ratio $(R / S)$ was positively correlated with SOM and negatively correlated with abandonment time. With the progress of succession, the hierarchical differentiation of the community was gradually obvious, and the community structure begun to complicate. The community better adapted to the arid environment and toward the local top community succession.

Keywords: abandoned farmland, community biomass, Loess Plateau, root/shoot ratio, soil nutrients 


\section{INTRODUCTION}

In the soil-vegetation system, vegetation and soil are unified organisms, which depend on each other and restrict each other. Soil affects the individual development and growth dynamics of plants and determines the type and distribution of plant community. Vegetation is an important soil-forming factor and also the basis of sustainable utilization of soil. In the process of growth, plants gradually improve the physical and chemical properties of soil by absorption and utilization of soil nutrients (Jiang, 2007; Chang et al., 2008; Jia et al., 2011; Hou and Fu, 2014; Kämpf et al., 2016; Yang et al., 2018; Li et al., 2019; Shang et al., 2019; Hou et al., 2020). Community biomass, as an important measure of ecosystem productivity, reflects the growth and development of plants and changes in their morphological characteristics and is also one of the important indicators to describe the community structure and function, which is a comprehensive reflection of the mutual competition between species and the mutual adaptation between species and the environment (Yan et al., 2006; Wang et al., 2009; Costa et al., 2014; Hou et al., 2020). Abandonment succession is the process of vegetation succession recovering to the top community after farmland abandonment. Many studies had shown that, during the vegetation succession after farmland abandonment, the species diversity and community productivity increased gradually, and the community structure tended to be complicated, which better improved the regional ecological environment (Jiang, 2007; Hou and Fu, 2014; Hülber et al., 2017; Du et al., 2020). There is a close relationship between vegetation restoration and soil nutrients. In the early stage of vegetation restoration, the regressive effect of community litter is weak, and the soil nutrient pool is in a state of loss. With the progress of vegetation restoration and community succession, vegetation litter gradually increases, supplementing the soil nutrient pool. At the same time, the increase in vegetation productivity also increases the soil nutrients; with the improvement of soil's physical and chemical properties, the productivity of vegetation is further improved, which promotes the process of vegetation succession (Yan et al., 2006; Du et al., 2009; Martinez et al., 2010; Fayez, 2012; Yang et al., 2018; Shang et al., 2019; Hou et al., 2020; Liu et al., 2020).

The Loess Plateau was once a major agricultural region in China. However, poor soil water conservation performance, serious soil erosion because of its special loess parent material, and reduced agricultural production had caused vegetation degradation and ecological environment deterioration, which seriously affect and restrict the local economic development and sustainable development of ecological environment (Jiang, 2007; Wang et al., 2009; Jia et al., 2011; Fang et al., 2018; Zhang et al., 2018; Li et al., 2019; Ge et al., 2020). In 1999, the Chinese government launched the "returning farmland to forest and grassland" ecological project, hoping to improve the deteriorating ecological environment by increasing the natural vegetation coverage. Therefore, researchers had done lots of research works on the succession process and the interaction between vegetation and soil of abandoned farmland. To study vegetation succession dynamics, it was necessary to clarify the allocation strategy of community biomass. The research in this area was still relatively weak for the reason that the research on below-ground biomass (BGB) was time-consuming and laborious. Jiang (2007) had found that the soil nutrient showed the fluctuation change of decreasing first and then rising during the succession of abandoned farmland. Liu (2008) had showed the opposite fluctuation trend. However, Du et al. (2008) found that the nutrient loss was serious in the few years after abandonment, and soil organic carbon, soil organic nitrogen, and soil microorganisms began to increase after 29 years of abandonment. The study of Mu et al. (2016) and Liu et al. (2020) showed that pioneer species plants invaded after farmland abandonment, the constructive species and dominant species were replaced constantly, and species abundance, coverage, and community biomass showed a fluctuating trend during the process of vegetation succession. Community biomass was an important parameter of plant community characteristics, and the root/shoot ratio (R/S) reflected the distribution ratio of community biomass in the process of plant growth (Tang et al., 2015; Du et al., 2020). Tang et al. (2015) showed that the R/S of plants was positively correlated with soil organic matter (SOM) and soil total nitrogen (STN) in the degraded grassland. Du et al. (2020) also showed soil nutrients were important factors affecting biomass distribution in the shrub grass community.

In this study, we selected the abandoned farmland in the hilly area of the Loess Plateau of Gansu Province as the research object. We studied the dynamic changes of vegetation, community biomass and its distribution proportion, and soil nutrients according to combined field investigation and indoor analysis by the method of spatial sequence instead of time sequence in the succession process of abandoned farmland vegetation. We tried to answer the following questions: 1) In the process of vegetation succession of abandoned farmland in the Loess Plateau, how vegetation adapted and responded to soil environmental changes? 2) How did the change in soil nutrients affect the allocation of community biomass?

\section{METHODS AND EXPERIMENT DESIGN}

\section{Study Site}

The study area lies at the Gaolan ecological and agricultural comprehensive test station of the Northwest Institute of EcoEnvironment and Resources, CAS, in the Loess Plateau of China $\left(36^{\circ} 13^{\prime} \mathrm{N}, 103^{\circ} 47^{\prime} \mathrm{E}\right)$. The site has an altitude of $1780-1820 \mathrm{~m}$ a.s.l. and an average annual temperature of $6.3^{\circ} \mathrm{C}$. The average annual precipitation is $263 \mathrm{~mm}, 70 \%$ concentrated in May to September, and the annual evaporation is $1785 \mathrm{~mm}$. The soil type of the experimental site is calcic soil (Wei et al., 2006). And the natural vegetation belongs to temperate desertification grassland. The main species are Reaumuria songarica, Ajania fruticulosa, Stipa breviflora, Lycium barbarum, Limonium sinense, Cleistogenes songorica, Salsola collina, Leymus secalinus, Artemisia sacrorum, Acroptilon repens, Peganum harmala, Artemisia capillaris, and Linum pallescens. 


\section{Methods and Experiment Design}

We chose four kinds of abandoned farmlands with the time of 1, 6, 12 , and 22 years to experiment. The community composition, community biomass, and soil nutrients of the four kinds of abandoned farmlands were studied by the method of space-time alternation. A $100 \mathrm{~m} \times 500 \mathrm{~m}$ experiment plot was selected for each kind of abandoned farmland. In 2011 and 2012, from May to August, a vegetation survey was carried out monthly, and five quadrats (repeats) were randomly selected in each experimental plot. Quadrats of $1 \mathrm{~m} \times 1 \mathrm{~m}$ were selected in the 1-, 6-, and 12-year abandoned farmlands (herbaceous vegetation), and $4 \mathrm{~m} \times 4 \mathrm{~m}$ was selected in the 22-year abandoned farmland (herbaceous and shrubby vegetation). The survey contents included species abundance, species coverage, and species frequency. In August, soil samples were taken by digging the profile to test soil moisture (SM, \%), soil $\mathrm{pH}$ value $(\mathrm{pH}), \mathrm{SOM}\left(\mathrm{g} \cdot \mathrm{kg}^{-1}\right)$, soil total nitrogen (STN, $\left.\mathrm{g} \cdot \mathrm{kg}^{-1}\right)$, and alkali hydrolyzable nitrogen (AHN, mg. $\mathrm{kg}^{-1}$ ). The depths of soil layers were $0-10 \mathrm{~cm}, 10-20 \mathrm{~cm}, 20-30 \mathrm{~cm}, 30-40 \mathrm{~cm}$, $40-50 \mathrm{~cm}$, and $50-60 \mathrm{~cm}$, totally six layers. In each experiment plot, nine points were selected by the S-type to take samples according to six soil layers, and then each three points was mixed into one, so each plot had $3 \times 6$ soil samples, with a total of 72 soil samples in our experiment. The soil cores were oven-dried to determine SM. Other soil samples were to be tested after air-drying for 4-5 days. The $\mathrm{pH}$ was determined by the glass electrode method (water: soil $=5: 1$ ). SOM was tested by the potassium dichromate volumetric method, STN was tested by semimicro-Kjeldahl, and AHN was tested by the alkaline diffusion method (Bao, 1986). In September, the aboveground biomass (AGB) was harvested in all quadrats and got constant weight after drying $\left(85^{\circ} \mathrm{C}, 48 \mathrm{~h}\right)$. The $\mathrm{BGB}$ was obtained by the excavation method. The soil mass of $1 \mathrm{~m} \times 1 \mathrm{~m} \times 0.6 \mathrm{~m}$ and $4 \mathrm{~m} \times 4 \mathrm{~m} \times 1 \mathrm{~m}$ under the quadrats was excavated, and the movable roots were picked up, washed, dried, and weighed $\left(105^{\circ} \mathrm{C}, 48 \mathrm{~h}\right)$.

\section{Data Analysis}

Microsoft Excel 2010 and statistical package SPSS 21.0 were used to analyze the data and results. Microsoft Excel statistical software was used to calculate the species importance value, Simpson index of species diversity, community biomass, and root/shoot ratio (R/S) of abandoned farmland. SPSS was used for one-way ANOVA, correlation analysis, and linear simulation analysis. We used one-way ANOVA (type III sum of squares) to analyze the significance of abandonment time on community biomass, SM, R/S, SOM, STN, and AHN. The significant differences were further analyzed by multiple comparisons (LSD). Correlation analysis was used to analyze the relationship among community biomass, abandonment time, SM, R/S, and soil nutrient indexes. The relationship between AGB and BGB was analyzed by linear regression.

The calculation formula of species importance value is as follows:

$$
\begin{aligned}
\text { Importance value }= & \text { Relative abundance }+ \text { Relative frequency } \\
& + \text { Relative coverage. }
\end{aligned}
$$

The Simpson index was used for species diversity, and the formula is as follows:

\begin{tabular}{|c|c|c|c|c|}
\hline \multirow{2}{*}{$\begin{array}{l}\text { Latin } \\
\text { name of species }\end{array}$} & \multicolumn{4}{|c|}{ Abandonment time } \\
\hline & 1 year & 6 years & 12 years & 22 years \\
\hline Heteropappus altaicus & 86.15 & 23.80 & - & 51.11 \\
\hline Artemisia capillaris & 116.96 & 35.03 & 26.52 & 52.52 \\
\hline Tragus racemosus & 27.76 & 107.06 & - & 42.06 \\
\hline Enneapogon borealis & 25.32 & 104.07 & - & 61.05 \\
\hline Halogeton arachnoideus & 30.11 & - & - & 17.41 \\
\hline Euphorbia humifusa & 9.61 & 33.58 & - & 28.26 \\
\hline Leymus secalinus & 37.56 & 33.75 & 190.08 & - \\
\hline Cirsium setosum & 31.29 & - & - & - \\
\hline Heteropappus altaicus & 21.38 & 8.04 & 30.61 & 6.78 \\
\hline Taraxacum officinale & 20.91 & 21.57 & - & - \\
\hline Cynanchum chinense & 20.06 & - & - & - \\
\hline Setaria viridis & 27.96 & - & - & 33.03 \\
\hline Convolvulus arvensis & 6.78 & 13.68 & - & - \\
\hline Plumbagella micrantha & 6.78 & 19.55 & - & - \\
\hline Eragrostis minor & 14.96 & - & - & - \\
\hline Lycium barbarum & 20.92 & - & - & 14.89 \\
\hline Medicago sativa & 6.83 & - & - & - \\
\hline Chenopodium acuminatum & - & 13.89 & 26.35 & 6.69 \\
\hline Sonchus oleraceus & - & 24.29 & 32.36 & - \\
\hline Acroptilon repens & - & - & 27.59 & - \\
\hline Stipa breviflora & - & - & - & 51.22 \\
\hline Cleistogenes songorica & - & - & - & 55.79 \\
\hline Salsola collina & - & - & - & 7.77 \\
\hline Peganum nigellastrum & - & - & - & 23.07 \\
\hline Caragna fruten & - & - & - & 9.01 \\
\hline Ajania fruticulosa & - & - & - & 10.06 \\
\hline Peganum harmala & - & - & - & 11.08 \\
\hline Linum pallescens & - & - & - & 8.15 \\
\hline Reaumuria songarica & - & - & - & 11.76 \\
\hline Limonium sinense & - & - & - & 18.90 \\
\hline Allium japonicum & - & - & - & 23.81 \\
\hline Astragalus membranaceus & - & - & - & 7.80 \\
\hline
\end{tabular}

TABLE 1 | Important value of species in four kinds of abandoned farmlands.

where $\mathrm{N}_{\mathrm{i}}$ is the number of individuals of species $\mathrm{i}$ and $\mathrm{N}$ is the sum of individuals of all species.

\section{RESULTS}

\section{Vegetation Characteristics of Abandoned Farmlands}

The species importance values of abandoned farmlands are shown in Table 1. The Simpson diversity indexes were as follows: 12 years $(0.36)<6$ years $(0.60)<1$ year $(0.64)<$ 22 years (0.79). In the early stage of abandonment, the species diversity was high because many opportunists began to invade at the early stage of abandonment. According to the importance value of species, the dominant species were Artemisia capillaris and Artemisia sacrorum of Asteraceae in the beginning of farmland abandonment. The other species were Tragus racemosus, Enneapogon borealis, Cirsium setosum, Lycium barbarum, Medicago sativa, Heteropappus altaicus, Halogeton arachnoideus, Eragrostis minor, Setaria viridis, Leymus secalinus, Cynanchum chinense, Taraxacum officinale, Convolvulus arvensis, Euphorbia humifusa, and Plumbagella 
TABLE 2 | Community composition of four abandoned farmlands.

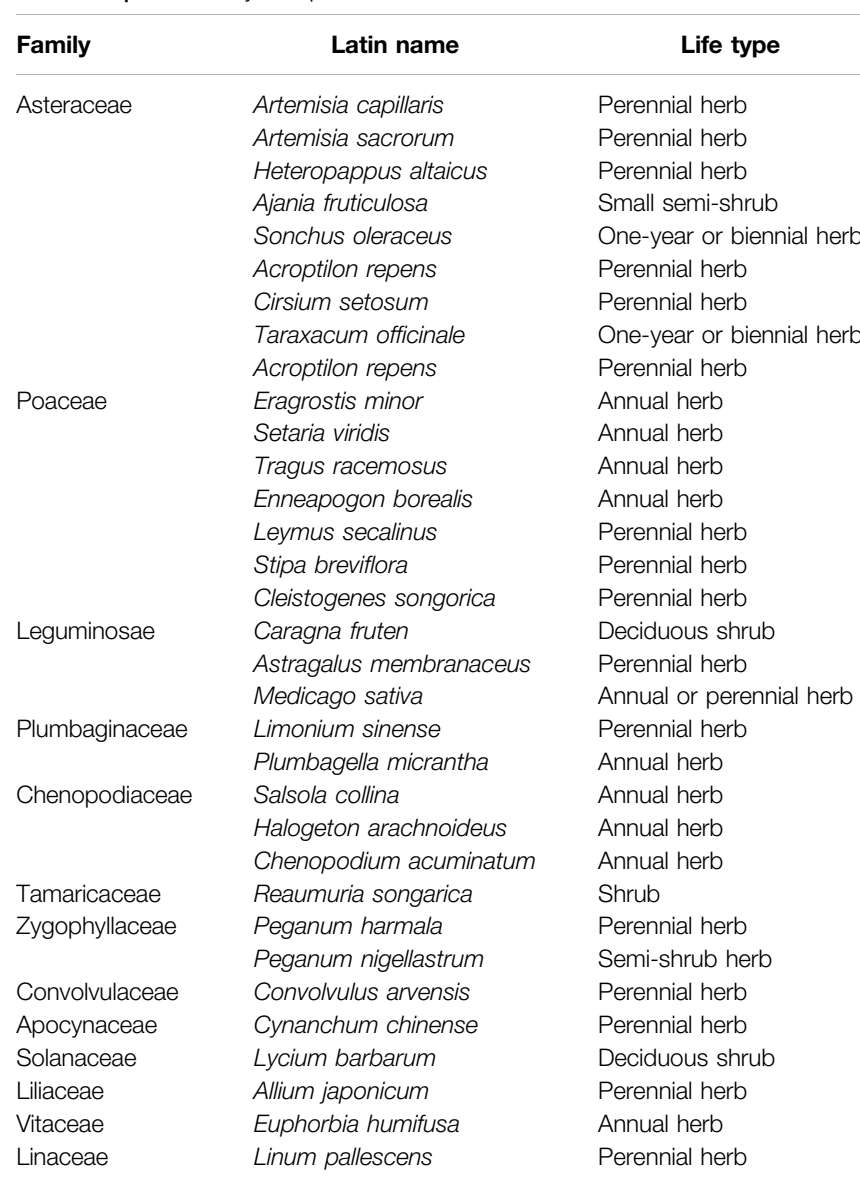

micrantha. After 6 years of abandonment, Tragus racemosus and Enneapogon borealis of Poaceae became the dominant species in the community. The other species were Artemisia capillaris, Artemisia sacrorum, Chenopodium acuminatum, Cirsium setosum, Sonchus oleraceus, Heteropappus altaicus, Enneapogon borealis, Tragus racemosus, Taraxacum officinale, Convolvulus arvensis, Euphorbia humifusa, and Plumbagella micrantha. Leymus secalinus was a common species in the early stage of abandonment and became the dominant species in the community after 12 years of abandonment. The other species were Artemisia capillaris, Chenopodium acuminatum, Heteropappus altaicus, Sonchus oleraceus, and Acroptilon repens. In this succession stage, the Simpson index was the lowest. With the progress of succession, Stipa breviflora and Cleistogenes songorica gradually became the dominant group of the community; at the same time, Artemisia capillaris, Artemisia sacrorum, Tragus racemosus, and Enneapogon borealis played an important role in the community after 22 years of abandonment. The other species were Allium japonicum, Euphorbia humifusa, Plumbagella micrantha, Chenopodium acuminatum, Setaria viridis, Salsola collina, Lycium barbarum, Linum pallescens, Peganum harmala, Peganum nigellastrum, Astragalus membranaceus, Heteropappus altaicus, Caragna fruten, Reaumuria songarica,
Ajania fruticulosa, and Limonium sinense. In this period of succession, the Simpson index was the highest, and some drought-tolerant species began to emerge in the community, such as Caragna fruten, Reaumuria songarica, Ajania fruticulosa, and Limonium sinense.

Vegetation investigation showed that there were 33 species in the experimental area, which belong to 13 families, respectively (Table 2). They were Asteraceae, Poaceae, Leguminosae, Plumbaginaceae, Chenopodiaceae, Tamaricaceae, Zygophyllaceae, Convolvulaceae, Apocynaceae, Solanaceae, Liliaceae, Vitaceae, and Linaceae. There were 15 species of plants in Gramineae and Compositae, which occupied $47 \%$ of the total community species. There were two species of plants in Plumbaginaceae and Zygophyllaceae, respectively, and three species of plants in Chenopodiaceae and Leguminosae, respectively. There was only one species of plant in other families. The order of species abundance of the four abandoned farmlands was 12 years $(6$ species $)<(12$ species $)<$ 1 year $(17$ species $)<22$ years ( 22 species), showing the trend of decreasing first and then increasing. The species of Compositae and Gramineae accounted for the largest proportion in the community in the whole experimental area. It showed that species of Compositae and Gramineae played an important role in the natural restoration of abandoned farmland vegetation in the experimental area.

\section{Dynamics of Community Biomass and R/S During Vegetation Succession}

The AGB of the four kinds of abandoned farmlands was $691 \mathrm{~g} \cdot \mathrm{m}^{-2}, \quad 1,036 \mathrm{~g} \cdot \mathrm{m}^{-2}, \quad 2,145 \mathrm{~g} \cdot \mathrm{m}^{-2}, \quad$ and $2,566 \mathrm{~g} \cdot \mathrm{m}^{-2}$, respectively, in 2011 and was $707 \mathrm{~g} \cdot \mathrm{m}^{-2}, 847 \mathrm{~g} \cdot \mathrm{m}^{-2}, 1957$ $\mathrm{g} \cdot \mathrm{m}^{-2}$, and 2,495 g. $\mathrm{m}^{-2}$, respectively, in 2012 (Figure 1A). The BGB of the four kinds of abandoned farmlands was $309 \mathrm{~g} \cdot \mathrm{m}^{-2}$, $402 \mathrm{~g} \cdot \mathrm{m}^{-2}, 604 \mathrm{~g} \cdot \mathrm{m}^{-2}$, and $535 \mathrm{~g} \cdot \mathrm{m}^{-2}$, respectively, in 2011 and was $334 \mathrm{~g} \cdot \mathrm{m}^{-2}, 424 \mathrm{~g} \cdot \mathrm{m}^{-2}, 659 \mathrm{~g} \cdot \mathrm{m}^{-2}$, and $466 \mathrm{~g} \cdot \mathrm{m}^{-2}$, respectively, in 2012 (Figure 1B). The AGB and BGB increased with the abandonment time. The one-way ANOVA showed that there was no significant difference in AGB $(\mathrm{F}=0.343, p>0.05)$ and $\mathrm{BGB}$ $(\mathrm{F}=0.022, p>0.05)$ between 2011 and 2012. There were significant differences in AGB $(\mathrm{F}=81.862, p<0.001)$ and BGB $(\mathrm{F}=21.727, p<0.001)$ among four kinds of abandoned farmlands. Multiple comparisons (LSD) of AGB showed that there were significant differences between that of 1-year abandoned farmland and that of 12-year and 20-year abandoned farmlands $(p<0.001)$. There were significant differences between that of 6-year abandoned farmland and that of 12-year and 20-year abandoned farmlands $(p<0.001)$. Multiple comparisons (LSD) of BGB showed that there were significant differences between that of 1-year abandoned farmland and that of other three abandoned farmlands $(p<$ $0.01)$. There was a significant difference between that of 6 -year and 12-year abandoned farmlands $(p<0.001)$ and between that of 12-year and 20-year abandoned farmlands $(p<0.01)$.

To illustrate the contributions to plant species from AGB and $\mathrm{BGB}$, we evaluated the relationship between AGB and BGB of all samples using the linear fitting method (Figure 2). A positive 

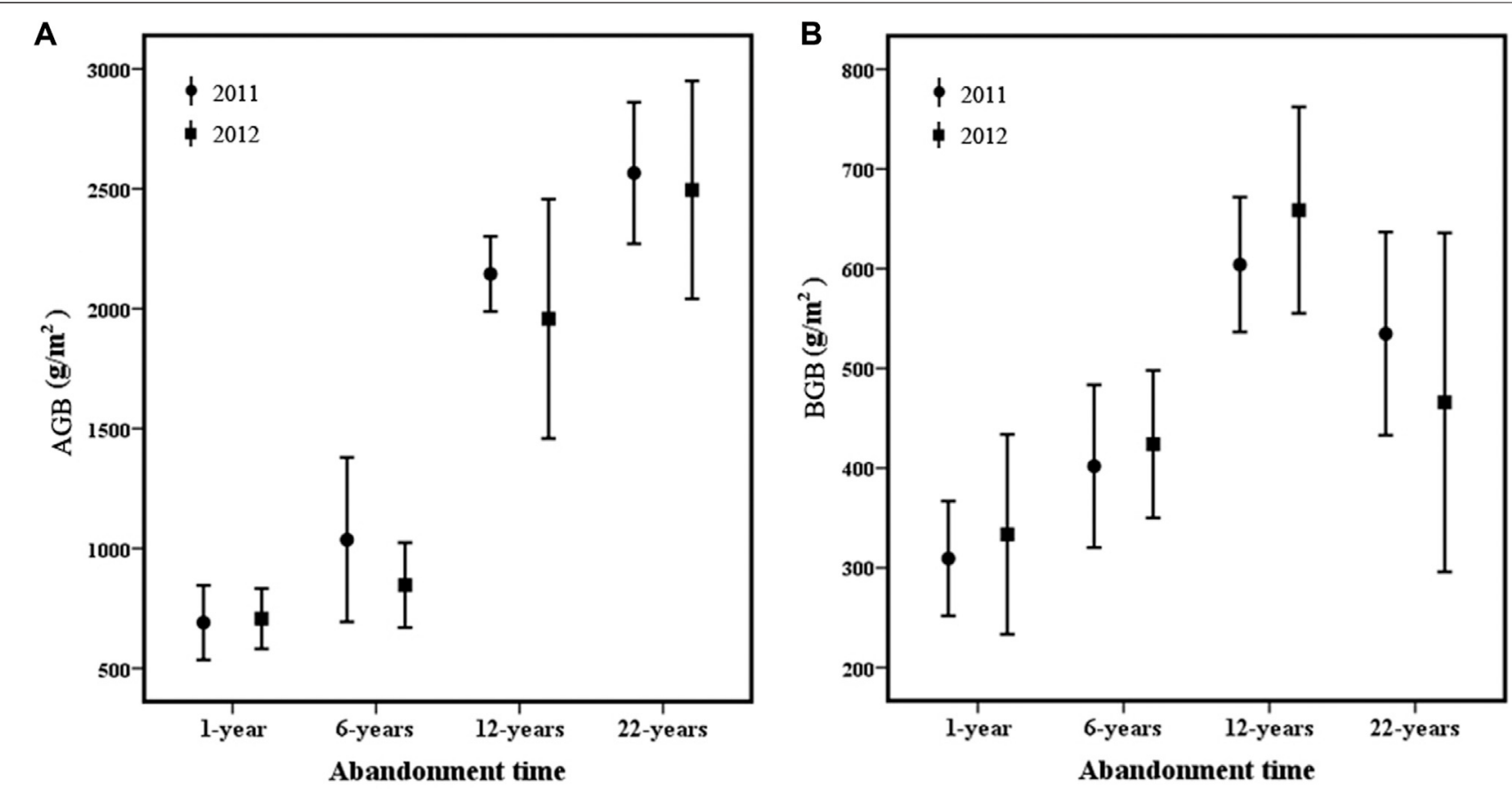

FIGURE 1 | AGB and BGB of four abandoned farmlands. (A) AGB in 2011 and 2012. (B) BGB in 2011 and 2012.

linear relationship between AGB and BGB $\left(R^{2}=0.426, p<0.01\right)$ indicates that the BGB could be estimated based on AGB.

The R/S of the four kinds of abandoned farmlands was 0.47 , $0.43,0.28$, and 0.25 in 2011 and was $0.48,0.51,0.35$, and 0.22 in 2012 (Figure 3). The R/S decreased with the abandonment time. The ANOVA showed that there was no significant difference in $\mathrm{R} / \mathrm{S}$ between 2011 and $2012(\mathrm{~F}=0.004, p>0.05)$ and were significant differences among four kinds of abandoned farmlands $(F=5.820, p<0.01)$. The multiple comparisons (LSD) showed that there was a significant difference between that of 1-year and 20-year abandoned farmlands $(p<0.05)$. There were significant differences between that of 6-year abandoned farmland and that of 12-year and 20-year abandoned farmlands $(p<0.05)$.

\section{Dynamics of pH, SM, SOM, STN, and Alkali Hydrolyzed Nitrogen During Vegetation Succession}

The $\mathrm{pH}$ of the four kinds of abandoned farmlands was $8.69 \pm 0.09$, $8.55 \pm 0.12,8.56 \pm 0.04$, and $8.53 \pm 0.20$, respectively. The soil appeared weakly alkaline, and $\mathrm{pH}$ decreased gradually with the abandonment time in the Loess Plateau. The SM of the four kinds of abandoned farmlands was 55.19, 43.52, 39.36, and $44.53 \%$ in 2011 and was $38.14,36.00,31.29$, and $33.67 \%$ in 2012 . It showed a trend of decreasing first and then increasing. The abandonment time and soil layer all had significant effect on SM (F = 15.31, $p<$ $0.001 ; \mathrm{F}=8.29, p<0.001$ ). Multiple comparisons (LSD) of four abandonment times showed that there was a significant difference between the SM of 1-year abandoned farmland and that of the other three abandoned farmlands $(p<0.001)$ and between that of the 6-year and 12-year abandoned farmlands.

The SOM of the four kinds of abandoned farmlands was $63.57 \mathrm{~g} \cdot \mathrm{kg}^{-1}, 64.88 \mathrm{~g} \cdot \mathrm{kg}^{-1}, 43.76 \mathrm{~g} \cdot \mathrm{kg}^{-1}$, and $53.25 \mathrm{~g} \cdot \mathrm{kg}^{-1}$ in 2011 and was $61.87 \mathrm{~g} \cdot \mathrm{kg}^{-1}, 67.02 \mathrm{~g} \cdot \mathrm{kg}^{-1}, 48.18 \mathrm{~g} \cdot \mathrm{kg}^{-1}$, and $50.66 \mathrm{~g} \cdot \mathrm{kg}^{-1}$ in 2012. SOM of four abandoned farmlands in different soil layers is shown in Figure 4A. SOM decreased with the soil layer in 0-60 cm, with surface accumulation. SOM increased first and then decreased with the abandonment time, and the highest SOM was found in the 6-year abandoned land. The one-way ANOVA of SOM showed that there was no significant difference between 2011 and $2012(\mathrm{~F}=0.24, p>0.05)$. The soil layer and abandonment time had significant effect on SOM ( $F=77.21$, $p<0.001 ; \mathrm{F}=62.58, p<0.001)$, and the interaction between the two had significant effect on SOM $(\mathrm{F}=2.43, p<0.05)$. Multiple comparisons (LSD) of SOM in six soil layers showed that there were significant differences among all soil layers $(p<0.001)$ except between $40-50 \mathrm{~cm}$ and $50-60 \mathrm{~cm}$ soil layers. Multiple comparisons (LSD) of SOM in four abandonment times showed that there was a significant difference between 1-year and 6-year abandonment times $(p<0.05)$, and the rest all had significant differences $(p<0.01)$.

The STN of the four kinds of abandoned farmlands was $4.18 \mathrm{~g} \cdot \mathrm{kg}^{-1}, 4.07 \mathrm{~g} \cdot \mathrm{kg}^{-1}, 3.55 \mathrm{~g} \cdot \mathrm{kg}^{-1}$, and $3.23 \mathrm{~g} \cdot \mathrm{kg}^{-1}$ in 2011 and was $3.67 \mathrm{~g} \cdot \mathrm{kg}^{-1}, 3.91 \mathrm{~g} \cdot \mathrm{kg}^{-1}, 3.36 \mathrm{~g} \cdot \mathrm{kg}^{-1}$, and $3.08 \mathrm{~g} \cdot \mathrm{kg}^{-1}$ in 2012. As shown in Figure 4B, STN in 2011 and 2012 decreased with the soil layer in 0-60 cm, with surface accumulation, similar to the SOM. With the abandonment time, STN continued to decline, except for the 6-year abandoned farmland in 2012. The one-way ANOVA of STN showed there was a significant 


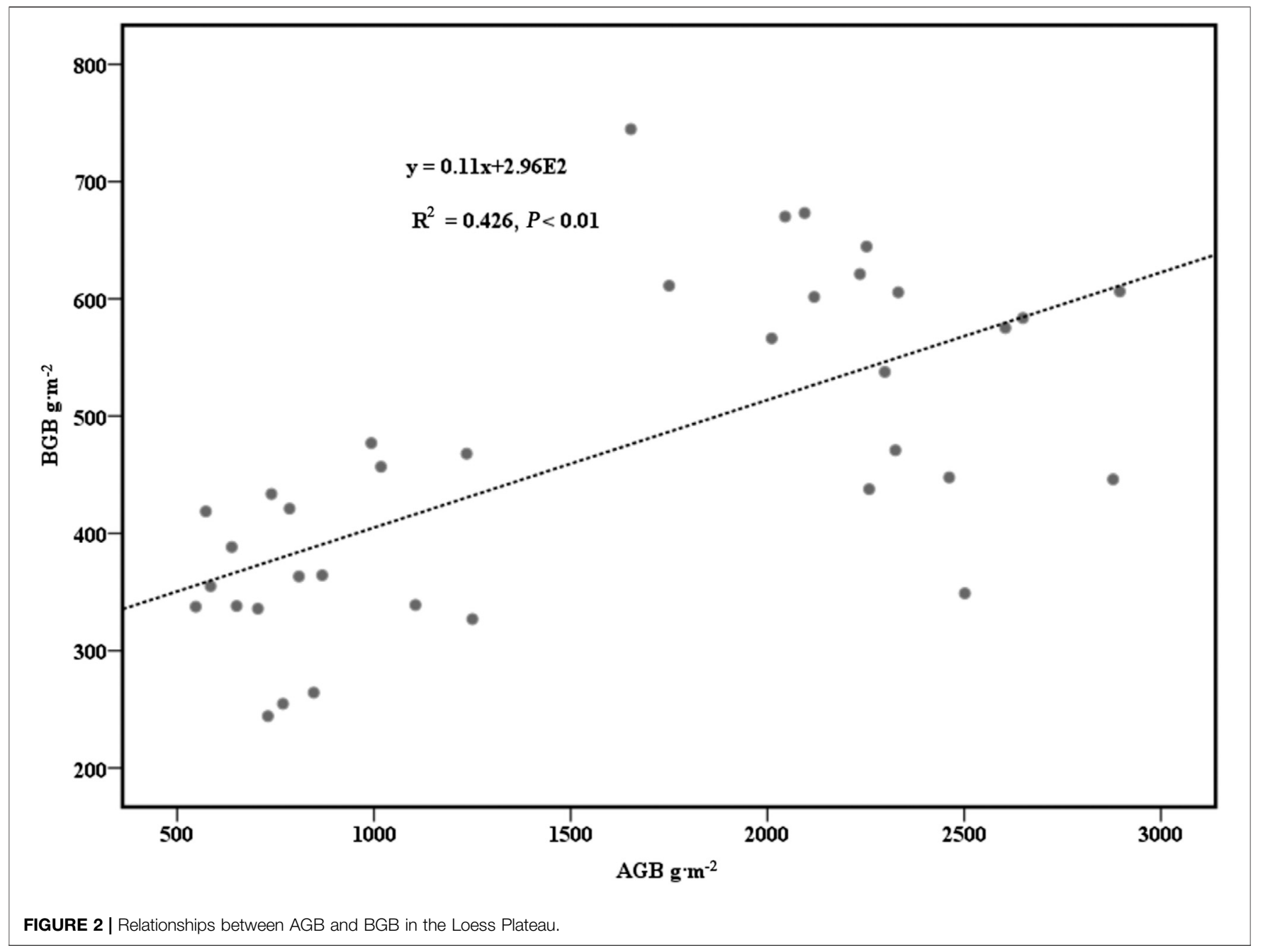

difference between 2011 and $2012(\mathrm{~F}=12.02, p<0.05)$. The soil layer and abandonment time had significant effect on STN (F = $57.62, p<0.001 ; \mathrm{F}=29.31, p<0.001)$, and the interaction between the two had significant effect on STN $(\mathrm{F}=2.84, p<0.05)$. Multiple comparisons (LSD) of STN in six soil layers showed that there were significant differences among all soil layers $(p<0.05)$ except between $40-50 \mathrm{~cm}$ and $50-60 \mathrm{~cm}$ soil layers. Multiple comparisons (LSD) of STN in four abandonment times showed that there were significant differences among all abandonment times $(p<0.001)$ except between 1 -year and 6year abandonment times.

The AHN of the four kinds of abandoned farmlands was $25.89 \mathrm{mg} \cdot \mathrm{kg}^{-1}, 25.17 \mathrm{mg} \cdot \mathrm{kg}^{-1}, 21.44 \mathrm{mg} \cdot \mathrm{kg}^{-1}$, and $12.67 \mathrm{mg} \cdot \mathrm{kg}^{-1}$ in 2011 and was $21.39 \mathrm{mg} \cdot \mathrm{kg}^{-1}, 23.28 \mathrm{mg} \cdot \mathrm{kg}^{-1}, 18.44 \mathrm{mg} \cdot \mathrm{kg}^{-1}$, and $12.83 \mathrm{mg} \cdot \mathrm{kg}^{-1}$ in 2012. As shown in Figure 4C, AHN decreased with the soil layer in $0-60 \mathrm{~cm}$ in 2011 and 2012, with surface accumulation, similar to the SOM and STN. With the abandonment time, AHN continued to decline, except for the 6-year abandoned farmland in 2012. The one-way ANOVA of AHN showed there was a significant difference between 2011 and $2012(\mathrm{~F}=12.49, p<0.05)$. The soil layer and abandonment time had significant effect on $\mathrm{AHN}(\mathrm{F}=88.49, p<0.001 ; \mathrm{F}=62.95$, $p<0.001)$, and the interaction between the two had significant effect on AHN ( $\mathrm{F}=5.61, p<0.001)$. Multiple comparisons (LSD) of AHN in six soil layers showed that there were significant differences among all soil layers $(p<0.05)$. Multiple comparisons (LSD) of AHN in four abandonment times showed that there were significant differences among all abandonment times $(p<0.001)$ except between 1 -year and 6 -year abandonment times.

\section{Correlation Analysis of Abandonment Time, AGB, BGB, R/S, SOM, STN, AHN, and SM}

The results of correlation analysis among AGB, BGB, R/S, abandonment time, SOM, STN, AHN, and SM are shown in Table 3. The abandonment time showed a significant correlation with the seven indexes measured $(p<0.01)$, among which it showed a positive correlation with the AGB and BGB. AGB was shown to have a positive correlation with $\mathrm{BGB}(p<0.01)$ and a negative correlation with other indexes. BGB was shown to have a negative correlation with SOM, STN, and SM $(p<0.01)$. SOM was shown to have a positive correlation with STN, AHN, R/S $(p<0.01)$, and SM $(p<0.05)$. STN was shown to have a positive 


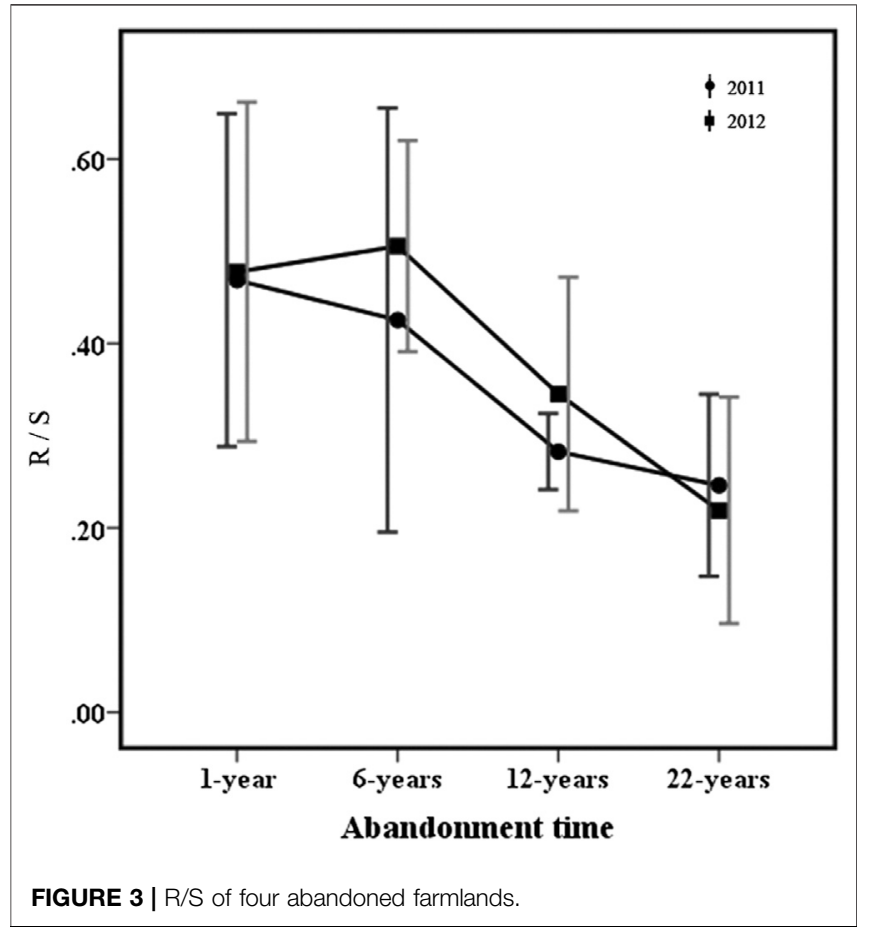

correlation with AHN and SM $(p<0.01)$. R/S was shown to have a positive correlation with AHN $(p<0.05)$.

\section{DISCUSSION}

Many studies had shown that the annual herbaceous plants would invade after farmland is abandoned. With the succession progress, the constructive species and dominant species of the plant community would change, and the richness and coverage of the community would show a fluctuating trend (Jiang, 2007; Chang et al., 2008; Kämpf et al., 2016; Hülber et al., 2017; Shang et al., 2019; Liu et al., 2020). In the early stage of abandonment, many free niches provided opportunities for pioneer species to invade and survive and species diversity was higher in the community. With the invasion of a large number of annual weeds, interspecific competition began to become fierce, leading to the withdrawal of some less competitive species from the weed community. As abandoned up to 12 years, the rhizomatous grass, Leymus secalinus, became the dominant population. Its strong tillering ability, big individuals, early turning green, and strong competitiveness, which inhibited the growth and reproduction of many annual and perennial herbs, resulted in the decline of the survival of some species in the
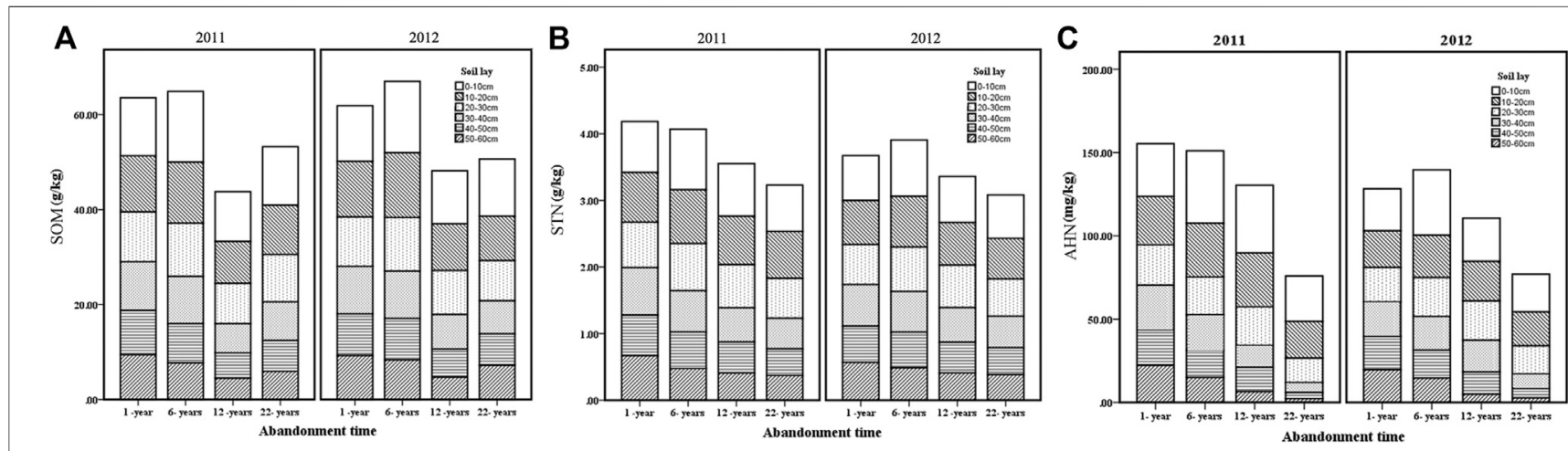

FIGURE 4 | SOM (A), STN (B), and AHN (C) of four abandoned farmlands in different soil layers.

TABLE 3 | Correlation analysis among abandonment time, AGB, BGB, R/S, SOM, STN, AHN, and SM.

\begin{tabular}{|c|c|c|c|c|c|c|c|c|}
\hline & AT & AGB & BGB & SOM & STN & $R / S$ & AHN & SM \\
\hline AT & 1 & & & & & & & \\
\hline AGB & $0.940^{b}$ & 1 & & & & & & \\
\hline $\mathrm{BGB}$ & $0.603^{b}$ & $0.653^{b}$ & 1 & & & & & \\
\hline SOM & $-0.629^{b}$ & $-0.729^{b}$ & $-0.624^{b}$ & 1 & & & & \\
\hline STN & $-0.732^{b}$ & $-0.721^{b}$ & $-0.521^{b}$ & $0.679^{b}$ & 1 & & & \\
\hline$R / S$ & $-0.683^{b}$ & $-0.788^{b}$ & -0.235 & $0.585^{b}$ & 0.404 & 1 & & \\
\hline $\mathrm{AHN}$ & $-0.853^{b}$ & $-0.784^{b}$ & -0.444 & $0.556^{b}$ & $0.897^{b}$ & $0.467^{a}$ & 1 & \\
\hline SM & $-0.481^{b}$ & $-0.448^{a}$ & $-0.482^{b}$ & $0.411^{a}$ & $0.583^{b}$ & 0.299 & $0.490^{a}$ & 1 \\
\hline
\end{tabular}

${ }^{a} p<0.05$

${ }^{b} p<0.01$ 
community and even death and emigration (Liu et al., 2007; Shi et al., 2008). Therefore, the community diversity decreased during this succession stage. After 22 years of abandonment succession, the Leymus secalinus community was replaced by a co-dominant community formed by Cleistogenes songorica and Stipa breviflora, more species survived, and species richness and vegetation coverage gradually increased. The co-dominant community had a stable structure, and the ecological environment gradually improved. Some more drought-tolerant shrubs, such as Reaumuria songarica and Ajania fruticulosa, began to emerge in the community. So far, the vegetation succession process of the herbaceous stage of abandoned farmland in the Loess Plateau had been completed. The results of this study were consistent with those of many previous studies. Many studies had shown that annual herbaceous plants invaded after farmland abandonment. With the succession of abandoned farmland, the constructive species and dominant species of the plant community were replaced, and the richness, coverage, and biomass of the community showed a fluctuating trend (Liu et al., 2007; Mu et al., 2016; Liu et al., 2020). Studies on abandoned farmland in the Loess Plateau by Du et al. (2008) showed that 6 years after abandonment, the community diversity of the mono-dominant community formed by Artemisia gmelinii or Artemisia giraldii decreased. After 15 years, the mono-dominant community was replaced by the drought-tolerant co-dominant community of Lespedeza davurica and Bothriochloa ischaemum, and the community diversity increased. Zhang et al. (2018) also found that species diversity had changed with abandonment time in the process of abandoning farming in the Loess Plateau. Our results were also similar to those of Jiang (2007) studies in the Loess Plateau. His results showed that species richness decreased to the lowest level seven years after abandonment. After 20 years of abandonment, species richness increased significantly to 26 species. Species richness changed with the abandonment time in the process of vegetation restoration. With the process of succession, the differentiation of community hierarchy was gradually obvious, and the community structure was becoming more and more complex, which can accommodate the coexistence of more species of multiple ecological types, and the succession had developed toward the local top community.

Many studies on abandoned farmland had found that AGB and BGB fluctuated with abandonment time during the process of vegetation restoration ( $\mathrm{Du}$ et al., 2008; Wang et al., 2009; Martinez et al., 2010; An et al., 2011; Costa et al., 2014; Yang et al., 2018). During the process of community succession, the change of community biomass is closely related to the community structure and dominant community. AGB distribution mainly relates to the competition for light resources, while BGB distribution mainly relates to the competition for soil nutrients (Du et al., 2008; An et al., 2011; Jia et al., 2011; Hou and Fu, 2014; Mu et al., 2016; Zhang et al., 2018). In this study, there were many vacant niches during the early stage of succession, and the competition was not fierce. A large number of annual herbs invaded, most of them were individually small and short-lived species, and they found it difficult to accumulate high $\mathrm{AGB}$ and $\mathrm{BGB}$ in a short growth period. Leymus secalinus, as a dominant population, replaced the previous weed community after 12 years of abandonment. It relied on its vigorous vegetative reproduction to expand its population, extended and expanded outward in space, and increased its quantity and volume in time through clonal tillers. So, it could obtain higher AGB and BGB in resource competition during this succession stage. This was also the main reason why Leymus secalinus became a dominant species in many grassland types (Liu et al., 2007; Shi et al., 2008). Du et al. (2008) and An et al. (2011) showed that the biomass of abandoned farmland decreased at first and then increased, while our results showed that biomass continued to increase in the whole succession process. The reason why our research results were not completely consistent with others was because of Leymus secalinus. In the middle stage of abandonment, it became the dominant species and obtained high biomass maintained the continuous increase of abandoned farmland biomass. After 22 years of abandonment, the dominant species of the community changed, gradually from the herbaceous community to the shrub community. More drought-tolerant species, such as Ajania fruticulosa, Lycium barbarum, and Reaumuria songarica, appeared in the community. The distribution proportion of AGB increased, while that of BGB decreased. The community contained multiple ecotypes of species to coexist, and the community structure tended to be stable. The community succession developed toward the local top community.

In the Loess Plateau, SM is the primary factor affecting vegetation restoration and reconstruction. Different species can obtain water from different depths of soils. Conversely, the distribution, storage, and change of water resources determine the species type and distribution (Jiang, 2007; Chang et al., 2008; Du et al., 2008; Yang et al., 2018). In this study, SM showed a downward trend, biomass continued to increase, and the two showed a negative correlation. The SM was higher during the early stage of abandonment due to the previous agricultural measures, and pioneer species could obtain higher biomass. The SM was consumed continuously during abandonment, and it reached the lowest level after abandonment for 12 years. However, the dominant species Leymus secalinus was not limited by SM. It could obtain deeper soil water for its well-developed root system and obtain high AGB and BGB. When abandoned for 22 years, higher community biomass was accumulated because of community diversity and vegetation coverage increased gradually. Wei et al. (2006) research also showed that, in the early stage of abandonment, loose soil could maintain high SM. With succession, SM decreased, and Leymus secalinus became an important factor affecting SM. SM fluctuated during the succession, and other researchers have similar results in the Loess Plateau (Jiang, 2007; Du et al., 2008).

The succession of community is a process of interaction between vegetation and soil. Vegetation affects the accumulation and distribution of soil nutrients through litter and root exudates, and soil nutrient content in turn affects the growth of vegetation (Du et al., 2009; Fayez, 2012; Li et al., 2019; Shang et al., 2019; Du et al., 2020; Ge et al., 2020; Liu et al., 2020). Jiang (2007) and Liu (2008) had found that the soil nutrient showed the fluctuation change of decreasing first and then 
increasing during the succession in the hilly area of the Loess Plateau. In this study, the SOM and STN decreased with the increase of abandonment time, which was not completely consistent with that reported in other studies. When abandoned after 12 years, the rhizomatous grass Leymus secalinus had gradually became the dominant species; its developed roots had strong competitiveness and effectively utilized and absorbed soil nutrients, causing soil nutrients to decline. At the same time, the decreased SOM and STN may be related to the soil nutrient loss caused by soil erosion in the Loess Plateau. In addition, the time series of the study was not long enough in this study. At 22 years of succession, the organic matter began to increase. With the increase of abandonment time, the total nitrogen content of soil is likely to increase. In the abandoned farmland in the Loess Plateau, Du et al. (2008) had found when the abandoned farmland was disturbed in the first few years, it showed obvious nutrition loss, and the growth of the below-ground part of the vegetation was limited. With the succession going on, SOM, STN, and soil microorganisms gradually increased, which was conducive to promoting the succession of the plant community. Hou (2012), Zhang et al. (2018), and Ge et al. (2020) also had similar research results in the Loess Plateau. The results had shown that the physical and chemical properties of the soil were gradually optimized and tended to benign development with the recovery of vegetation during the succession of abandoned farmland.

The R/S reflects the distribution ratio of photosynthesis products in plants. Its change is a response strategy for plants to environmental changes. Soil nutrient is one of the factors affecting the R/S (Yan et al., 2006; Du et al., 2008; Costa et al., 2014; Tang et al., 2015; Fang et al., 2018; Yang et al., 2018). The results of Tang et al. (2015) had shown that the R/S of plants was positively correlated with SOM and STN in the degraded grassland of Yanchi County in Ningxia. Fang et al. (2018) had found that higher soil nutrients played an important role in promoting the growth of fine roots and increasing the distribution of BGB in the loess hilly area of Shanxi. Du et al. (2020) had found there was a significant correlation between soil available phosphorus and community biomass, and between SOM and R/S, indicating that soil factors were important factors affecting biomass distribution in the shrub grass community in Northwest Hebei Province. Our study found that the R/S was positively correlated with SOM, but not with STN, which was consistent with the previous results. When plants distribute biomass in different organs, they will adopt the survival strategy of absorbing soil water, soil nutrients, and light resources to the maximum extent, so as to achieve the maximum growth rate during the process of growth (Yan et al., 2006; Wang et al., 2009; Costa et al., 2014). When the soil nutrient resources are

\section{REFERENCES}

An, H., Yang, X. G., Liu, B. R., Li, X. B., He, X. Z., and Song, N. P. (2011). [Changes of Plant Community Biomass and Soil Nutrients during the Vegetation Succession on Abandoned Cultivated Land in Desert Steppe Region]. Ying Yong Sheng Tai Xue Bao. 22 (12), 3145-3149. doi:10.13287/j.1001-9332.2011.0467 insufficient, plants will adjust their growth strategies to adapt to environmental changes by changing the AGB and BGB allocation.

\section{CONCLUSION}

In this experiment, the succession trend of abandoned farmland was as follows: The vegetation was the weed community of Heteropappus altaicus + Artemisia capillaris in the beginning of the abandonment stage and became the weed community of Tragus racemosus + Enneapogon borealis after 6 years of abandonment. Then, Leymus secalinus became the dominant population in the community after 12 years of abandonment. With the succession time reaching 22 years, the vegetation of abandoned farmland became a common advantageous community of Cleistogenes songorica + Stipa breviflora. The AGB and BGB of abandoned farmland increased gradually with the abandonment time. The growth rate of $\mathrm{AGB}$ and $\mathrm{BGB}$ reached 118 and 53\%, respectively, during 6-12 years of abandonment. The R/S of the abandoned farmland was less than 1 and decreased during the process of succession. The $\mathrm{pH}$ was more than 8 , and the soil appeared weak alkaline in the Loess Plateau. SM decreased gradually with the succession time and reached the lowest level after 12 years of abandonment. SOM showed a trend of increasing first and then decreasing, and STN and $\mathrm{AHN}$ were decreased during the process of succession.

\section{DATA AVAILABILITY STATEMENT}

The raw data supporting the conclusions of this article will be made available by the authors, without undue reservation.

\section{AUTHOR CONTRIBUTIONS}

MG designed and arranged the experiment and wrote the manuscript. SL modified the manuscript. HD participated in the field experiment. TW is our project leader, who was in charge of the experiment in general. ZG participated in data collation and statistics analysis.

\section{FUNDING}

This study was supported by the Project of National Key Research and Development Program of China "Assessment on evolution trend and stability of desertified land in the semiarid region of northern China."

Bao, S. D. (1986). Soil Agrochemical Analysis [M]. Beijing: China Agricultural Publishing House.

Chang, J. F., Liu, H. J., Zhao, M., Han, F. G., Zhong, S. N., and Tang, J. N. (2008). Three Stages of Degeneration Succession of Desert Vegetation in Minqin. Chin. Agric Sci Bull. 24 (6), 389-395.

Costa, T. L., Sampaio, E. V. S. B., Sales, M. F., Accioly, L. J. O., Althoff, T. D., Pareyn, F. G. C., et al. (2014). Root and Shoot Biomasses in the Tropical Dry 
forest of Semi-arid Northeast Brazil. Plant Soil. 378, 113-123. doi:10.1007/ s11104-013-2009-1

Du, F., Liang, Z. S., Xu, X. X., Zhang, X. C., and Shan, L. (2008). Spatial Heterogeneity of Soil Nutrients and Above-Ground Biomass in Abandoned Old-fields of Loess Hilly Region in Northern Shaanxi, China. Acta Ecol. Sinica. 28 (1), 13-22. doi:10.1016/s1872-2032(08)60017-7

Du, J. H., Yan, P., Ding, L. G., Er, Y. H., and Zhu, M. J. (2009). Soil Physical and Chemical Properties of Nitraria Tangutorun Nebkhas Surface an Different Development Stages in Minqin Oasis. J. Desert Res. 29 (2), 248-253.

Du, M. Q., Zhang, H. S., Peng, D., and Zha, T. G. (2020). Distribution of ShrubHerb Community Biomass and its Relationship with Soil Factors in Middle and Low Mountainous Areas of Northwest Hebei Province. Pratac Sci. 37 (1), 1-9. doi:10.11829/j.issn.1001-0629.2019-0227

Fang, Z., Zhang, S. K., Liu, H. W., Jiao, F., and Zhang, J. (2018). Distribution of Herbaceous Community Biomass and its Relationship with Influencing Factors in the Loess Hilly Region. Acta Pratac Sinica. 27 (2), 26-35. doi:10.11686/ cyxb2017152

Fayez, R. (2012). Soil Properties and C Dynamics in Abandoned and Cultivated Farmlands in a Semi-arid Ecosystem. Plant Soil. 351, 161-175. doi:10.1007/ s11104-011-0941-5

Ge, J. M., Wang, S., Fan, J., Gongadze, K., and Wu, L. H. (2020). Soil Nutrients of Different Land-Use Types and Topographic Positions in the Water-Wind Erosion Crisscross Region of China's Loess Plateau. Catena. 184, 1-10. doi:10.1016/j.catena.2019.104243

Hou, D., Bolan, N. S., Tsang, D. C. W., Kirkham, M. B., and O'Connor, D. (2020). Sustainable Soil Use and Management: An Interdisciplinary and Systematic Approach. Sci. Total Environ. 729, 138961. doi:10.1016/j.scitotenv.2020.138961

Hou, J., and Fu, B. (2014). Vegetation Dynamics during Different Abandoned Year Spans in the Land of the Loess Plateau of China. Environ. Monit. Assess. 186, 1133-1141. doi:10.1007/s10661-013-3444-4

Hou, X. R. (2012). The Spatial Distribution and Storage of Soil Organic Carbon and Nitrogen of Hilly Region of Loess Plateau. Yangling: Northwest Agriculture \& Forestry University

Hülber, K., Moser, D., Sauberer, N., Maas, B., Staudinger, M., Grass, V., et al. (2017). Plant Species Richness Decreased in Semi-natural Grasslands in the Biosphere Reserve Wienerwald, Austria, over the Past Two Decades, Despite Agri-Environmental Measures. Agric. Ecosyst. Environ. 243, 10-18. doi:10.1016/j.agee.2017.04.002

Jia, X., Shao, M., and Wei, X. (2011). Richness and Composition of Herbaceous Species in Restored Shrubland and Grassland Ecosystems in the Northern Loess Plateau of China. Biodivers Conserv. 20, 3435-3452. doi:10.1007/s10531-011-0130-0

Jiang, J. P. (2007). Co-variation of Vegetation and Soil Quality during Ecosystem Restoration in the Hilly Region of the Semiarid Loess Plateau. Lanzhou: Lanzhou University

Kämpf, I., Mathar, W., Kuzmin, I., Hölzel, N., and Kiehl, K. (2016). Post-soviet Recovery of Grassland Vegetation on Abandoned fields in the forest Steppe Zone of Western Siberia. Biodivers Conserv. 25, 2563-2580. doi:10.1007/ s10531-016-1078-x

Li, J. W., Liu, Y. L., Hai, X. Y., Shangguan, Z. P., and Deng, L. (2019). Dynamics of Soil Microbial C:N:P Stoichiometry and its Driving Mechanisms Following Natural Vegetation Restoration after farmland Abandonment. Sci. Total Environ. 693, 1-11. doi:10.1016/j.scitotenv.2019.133613
Liu, W. H., Zhou, Q. P., and Yan, H. P. (2007). Research Progress on the Propagation Path of Rhizome Grasses. Chin. Qinghai J. Anim. Veter Sci 37 (2), 46-49.

Liu, Y. (2008). Effects of Vegetation Restoration on Soil Quality in Yangou Catchment in Hilly-Gully Region of the Loess Plateau. Xi'an: Northwest Agriculture \& Forestry University

Liu, Y., Zhu, G., Hai, X., Li, J., Shangguan, Z., Peng, C., et al. (2020). Long-term forest Succession Improves Plant Diversity and Soil Quality but Not Significantly Increase Soil Microbial Diversity: Evidence from the Loess Plateau. Ecol. Eng. 142, 105631. doi:10.1016/j.ecoleng.2019.105631

Martinez, D. E., Ferrandis, P., and Escudero, A. (2010). Secondary Old-Field Succession in an Ecosystem with Restrictive Soils: Does Time from Abandonment Matter? Appl. Veg Sci. 13, 234-248. doi:10.1111/j.1654109X.2009.01064.X

Mu, L., Zhang, P. J., Liu, Y. H., Liu, X. C., Ren, Y. F., Wang, B., et al. (2016). Effect of Restoration Measures on Herbaceous Community Characteristics of Abandoned Land in Desert Steppe of Inner Mongolia. Chin. Agric Sci Bull. 32 (16), 110-116.

Shang, Z. H., Cao, J. J., Degen, A. A., Zhang, D. W., and Long, R. J. (2019). A Four Year Study in a Desert Land Area on the Effect of Irrigated, Cultivated Land and Abandoned Cropland on Soil Biological, Chemical and Physical Properties. Catena. 175, 1-8. doi:10.1016/j.catena.2018.12.002

Shi, H. X., Zhou, Q. P., Yan, H. P., Liu, W. H., and Yang, Y. L. (2008). Preliminary Study on the Space and Time Expanding of Three Rhizometype Grasses in Clonal Reproduction Stage. Pratac Sci. 25 (5), 127-132.

Tang, Z. S., An, H., and Shang Guan, Z. P. (2015). Effects of Desertification on Soil Nutrients and Root-Shoot Ratio in Desert Steppe. Acta Agrestia Sinica. 23 (3), 463-468. doi:10.11733/j.issn.1007-0435.2015.03.005

Wang, G., Liu, G., and Xu, M. (2009). Above- and Belowground Dynamics of Plant Community Succession Following Abandonment of farmland on the Loess Plateau, China. Plant Soil. 316, 227-239. doi:10.1007/s11104-008-9773-3

Wei, X. H., Xie, Z. K., and Duan, Z. H. (2006). Vegetation Rehabilitation and Soil Moisture Control in Abandoned Plowlands on Western Loess Plateau. J. Desert Res. 26 (4), 590-595.

Yan, E.-R., Wang, X.-H., and Huang, J.-J. (2006). Shifts in Plant Nutrient Use Strategies under Secondary forest Succession. Plant Soil. 289, 187-197. doi:10.1007/s11104-006-9128-x

Zhang, W., Ren, C., Deng, J., Zhao, F., Yang, G., Han, X., et al. (2018). Plant Functional Composition and Species Diversity Affect Soil C, N, and P during Secondary Succession of Abandoned farmland on the Loess Plateau. Ecol. Eng. 122, 91-99. doi:10.1016/j.ecoleng.2018.07.031

Conflict of Interest: The authors declare that the research was conducted in the absence of any commercial or financial relationships that could be construed as a potential conflict of interest.

Copyright $\odot 2021 \mathrm{Gu}$, Liu, Duan, Wang and Gu. This is an open-access article distributed under the terms of the Creative Commons Attribution License (CC BY). The use, distribution or reproduction in other forums is permitted, provided the original author(s) and the copyright owner(s) are credited and that the original publication in this journal is cited, in accordance with accepted academic practice. No use, distribution or reproduction is permitted which does not comply with these terms. 